\title{
Transgenic Mice with Expression of Elevated Levels of Copper-Zinc Superoxide Dismutase in the Lungs are Resistant to Pulmonary Oxygen Toxicity
}

Carl W. White, Karen B. Avraham, ${ }^{*}$ Paul F. Shanley, and Yoram Groner*

Department of Pediatrics, National Jewish Center for Immunology and Respiratory Medicine, and Department of Pathology, University of Colorado Health Sciences Center, Denver, Colorado 80206; and *Department of Molecular

Genetics and Virology, The Weizmann Institute of Science, Rehovot, Israel

\begin{abstract}
To test the hypothesis that increases in lung superoxide dismutase can cause tolerance to pulmonary oxygen toxicity, we studied transgenic mice which constitutively express elevated levels of the human copper-zinc SOD (CuZnSOD). Upon exposure to hyperoxia ( $>99 \% \mathrm{O}_{2}, 630$ torr) the transgenic CuZnSOD mice showed increased survival, decreased morphologic evidence of lung damage such as edema and hyaline membrane formation, and reduction in the number of lung neutrophils. During continuous exposure to oxygen, both control and transgenic animals who successfully adapted to hyperoxia showed increased activity of lung antioxidant enzymes such as glutathione peroxidase (GPX), glutathione reductase (GR), and glucose-6-phosphate dehydrogenase (G6PD), whereas superoxide dismutase activity remained unchanged. The results show that expression of elevated levels of $\mathrm{CuZnSOD}$ decreases pulmonary oxygen toxicity and associated histologic damage and mortality. (J. Clin. Invest. 1991. 87:2162-2168.) Key words: glutathione peroxidase • glucose-6-phosphate dehydrogenase $\bullet$ glutathione reductase $\bullet$ superoxide $\cdot$ inflammation
\end{abstract}

\section{Introduction}

The potential clinical use of superoxide dismutase (SOD) ${ }^{1}$ to decrease pulmonary oxygen toxicity has been investigated in several systems. In a study of humans exposed to increased inspired oxygen tensions for prolonged periods, administering bovine superoxide dismutase (SOD) subcutaneously in infants with respiratory distress syndrome palliated bronchopulmonary dysplasia (1). However, a detailed morphologic study done in newborn rats developing bronchovascular dysplasia as a result of early exposure to oxygen did not demonstrate any

Parts of this work were presented in a plenary session of the Western Society for Pediatric Research, Carmel, CA, February 1990, and at the World Conference on Lung Health/American Thoracic Society Meeting, Boston, MA, May 1990.

Address correspondence to Carl W. White, M.D., Department of Pediatrics, National Jewish Center for Immunology and Respiratory Medicine, 1400 Jackson St., Denver, CO 80206.

Received for publication 15 November 1990 and in revised form 1 March 1991.

1. Abbreviations used in this paper: G6PD, glucose-6-phosphate dehydrogenase; GPX, glutathione peroxidase, GR, glutathione reductase, SOD, superoxide dismutase.

J. Clin. Invest.

(C) The American Society for Clinical Investigation, Inc.

$0021-9738 / 91 / 06 / 2162 / 07 \quad \$ 2.00$

Volume 87, June 1991, 2162-2168 palliative effect of SOD injections despite large increases in extracellular SOD. No benefit, in terms of decreasing vascular remodeling or developmental failure due to short-term exposure to hyperoxia, was afforded by extracellular SOD (2). In pulmonary epithelial and vascular endothelial cells, important targets of hyperoxic damage, SOD delivered in liposomes to increase intracellular SOD decreased the toxicity due to hyperoxic exposure $(3,4)$. Liposome-encapsulated SOD has also been effective in decreasing pulmonary $\mathrm{O}_{2}$ toxicity in both adult and newborn rats when delivered intravenously, intratracheally, or intraperitoneally (5-7). In these models, concomitantly administered, liposomal catalase has provided optimal tolerance.

In a variety of other models for tolerance to hyperoxic lung damage, increases in lung superoxide dismutase activities also have been identified, frequently with associated increases in enzymes of the glutathione redox cycle and/or catalase (8-14). Both mitochondrial (MnSOD) and cytoplasmic (CuZnSOD) forms of SOD have been suggested to be important in multiple models of tolerance to pulmonary oxygen toxicity in adult rats and in newborns of several species. The potential relative importance of each SOD in affording lung protection is unclear. Although enzymes of the glutathione redox cycle also have been noted frequently to be elevated, these changes have been reported less consistently than those for the superoxide dismutases. It is difficult to separate the relative contribution of increases in detoxifiers of peroxides from that of SOD in many of these models. Because additional stresses or lung biochemical changes are induced commonly in animals by the methods producing tolerance, novel approaches are needed to define more specifically the relative importance of each antioxidant enzyme in vivo.

Transgenic animals offer a new means for more selectively altering antioxidant enzymes. We examined the responses to hyperoxia of a previously characterized transgenic mouse with constitutive expression of elevated levels of human copper-zinc superoxide dismutase (CuZnSOD). We found that these mice had an increased development of tolerance to hyperoxia associated with decreased histopathologic evidence of lung damage including edema, hyaline membrane formation, and inflammation.

\section{Methods}

Transgenic mice. Transgenic mice harboring the human CuZnSOD gene were produced by microinjection of fertilized eggs with a linear 14.5-kb fragment of human genomic DNA containing the entire $\mathrm{CuZnSOD}$ gene, including its regulatory sequences, as previously described $(15,16)$. TgHS-51 progeny, as used in these studies, contained five copies of the human CuZnSOD gene in their genomes. The mice used were derived from outbred matings between CBYB/6 [(BALB/ cxC57BL/6J $\left.) \mathrm{F}_{1}\right]$ and $\mathrm{B} 6 \mathrm{D} / 2\left[(\mathrm{C} 57 \mathrm{BL} / 6 \mathrm{JxDBA}) \mathrm{F}_{1}\right]$ mice. They were kept under virus-free conditions; routine serologies were performed. 
Transgenic mice with stable expression of elevated levels of human CuZnSOD were bred in a virus-free animal facility at Colorado State University. TgHS-51 homozygote, heterozygote, and control mice (15), identified by Southern blot analysis (16), SOD activity gel (16, 17), and by pedigree analysis done by characterizing their offspring with the latter method, were used to found the colony in Colorado using mice from Rehovot. Transgenic heterozygote mice were bred using known homozygote and control parents, and heterozygote and control offspring were characterized using red blood cell superoxide dismutase assays (see below). Alternatively, mice expressing the human CuZnSOD gene were identified by polyacrylamide gel analysis of CuZnSOD activity (see below; references 15-17). Additional CBYB6 $\times$ B6D2 control mice were bred from the parent strains (Bantin and Kingman, San Francisco, CA). Thereafter, additional experimental animals were obtained by breeding homozygote, heterozygote, or control males with control females, and offspring were identified with red blood cell SOD assays and SOD activity gel electrophoresis.

Red blood cell superoxide dismutase activity assay. Mice were anesthetized by inhalation of metophane, and blood was removed with capillary tubes from the retroorbital plexus. Whole blood was diluted and red cells lysed in $50 \mathrm{mM}$ potassium phosphate buffer $(\mathrm{pH} 7.8)$ containing $0.1 \%$ NP40. After overnight dialysis to remove low molecular weight substances which reduce ferricytochrome $c$, total SOD activity (pH 7.8) was measured (18).

SOD activity gel electrophoresis. Tissue homogenates $(\sim 10-20 \mu \mathrm{g}$ tissue) or red blood cell hemolysates (1:20, vol:vol in $50 \mathrm{mM}$ potassium phosphate, $\mathrm{pH} 7.8 ; 20 \mu \mathrm{l}$ ) were loaded onto a $10 \%$ acrylamide gel and electrophoresed for $\sim 3 \mathrm{~h}$ at $150 \mathrm{~V}$. Staining for SOD enzymatic activity was done as described elsewhere (17) except that the gels were soaked in nitroblue tetrazolium for $20 \mathrm{~min}$, followed by additional soaking for $15 \mathrm{~min}$ in tetramethylethylenediamine/riboflavin in potassium phosphate buffer. Distinct bands representing mouse SOD, mouse-human SOD heterodimer, human SOD, and hemoglobin were identified on these gels.

Exposure to hyperoxia. Mice were housed in plexiglas chambers flushed continuously with oxygen from a liquid source (10 liter/min) and maintained at Denver atmospheric pressure (630 torr) or at sea level atmospheric pressure ( 760 torr) by regulation of chamber outflow with a water manometer. This provided sufficient flow to maintain measured oxygen concentration consistently $>99 \%$ and $\mathrm{CO}_{2}$ concentration $<0.5 \%$. Relative humidity was $50-70 \%$. Lighting was on a $12-\mathrm{h}$ on/off cycle. Food and water were provided ad libitum. Mice were observed every $12 \mathrm{~h}$ for evidence of respiratory distress and survival.

Unless males were housed individually, fighting stress contributed significantly to the mortality of male mice in both normoxic and hyperoxic environments. Therefore, limited numbers of exposures of males to hyperoxia were done. Female mice were used for all subsequent studies of lung morphology and biochemistry.

Lung morphology studies. After exposure to hyperoxia for $168 \mathrm{~h}$, or less in those mice that expired or showed severe respiratory distress, mice were euthanized with pentobarbital $(120 \mathrm{mg} / \mathrm{kg}$ i.p. $)$ and tracheostomy and placement of a tracheal cannula were rapidly performed. Lungs were fixed by intratracheal infusion of buffered glutaraldehyde $(2.5 \% ; 100 \mathrm{mM}$ potassium phosphate, $\mathrm{pH} 7.4)$ in situ at $15 \mathrm{~cm}$ $\mathrm{H}_{2} \mathrm{O}$ pressure. After 30 min, lungs were dissected free, immersed in fixative, and coded for further processing and analysis. Histologic damage, as indicated by accumulation of edema fluid, hyaline membrane formation, and septal thickening, was qualitatively determined by a pathologist (P. F. Shanley), using the coded specimens. Each sample was assessed specifically both for the presence or absence of significant pulmonary edema and of hyaline membranes. Lung neutrophils were counted on hematoxylin-eosin stained sections (5- $\mu \mathrm{m}$ sections).

Lung biochemical studies. After lethal injection of pentobarbital, lungs of mice were perfused via the pulmonary artery with PBS (pH 7.4, $5 \mathrm{mM}$ potassium phosphate). Right lungs were homogenized for $30 \mathrm{~s}\left(4^{\circ} \mathrm{C}\right)$ in $50 \mathrm{mM}$ potassium phosphate, $\mathrm{pH} 7.8$, using a Virtishear (Virtis, Gardiner, NY). Lungs were centrifuged for $10 \mathrm{~min}(15,000 \mathrm{~g})$. The supernatant was retained for enzyme activity measurements, and the pellet for insoluble protein determination (19). Activities of catalase (20), glutathione peroxidase (21) and reductase (21), and glucose-6phosphate dehydrogenase (21) were determined spectrophotometrically. Lung antioxidant enzyme activities were corrected for activity due to blood contamination using the dithionite-sensitive reduction of hemoglobin (22). After overnight dialysis of an aliquot of the lung homogenate, SOD activity was measured spectrophotometrically (18). In aliquots studied without dialysis, total SOD, CuZnSOD, and MnSOD activities also were determined based on the differential activity of $\mathrm{CuZnSOD}$ in the presence and absence of increased concentrations of cyanide $(5 \mathrm{mM})$. This more sensitive assay system contained diethylenetriaminepentaacetic acid $(1 \mathrm{mM})$, bathocuproinedisulfonic acid $(0.06 \mathrm{mM})$, and bovine liver catalase $(1.25 \mathrm{U} / \mathrm{ml})$ in addition to xanthine, xanthine oxidase, and nitroblue tetrazolium (23). DNA was determined using the left lung (24).

Statistical analyses. For each sex/age/pressure combination, the survival function of each group (control, transgenic) was estimated using the Kaplan-Meier method, and then the two distributions were compared using a Wilcoxon test (Gehan's test, 25). Mean ( \pm SEM) survival times are reported for studies in which all members of both groups had died by the end of the study.

Data from histopathologic studies were compared using the Pearson Chi-square analysis. Lung antioxidant enzyme activity data were analyzed using a two-way factorial analysis of variance to examine for group- and time-related main effects and a group-by-time interaction. If the interaction was found to be significant, independent sample Student's $t$ tests were done for group differences at each level of time. Likewise, time differences within each group were examined with $t$ tests or one-way ANOVA as appropriate. If the interaction was not found to be significant, main effects from the two-way ANOVA were examined. Time effects were evaluated using a linear contrast in the means, after the ANOVA, using defined a priori contrasts (26). A $P$ value $<0.05$ was taken as the level of significance for all analyses.

\section{Results}

Survival. The survival of young (2.5 mo age), female transgenic heterozygote mice $(11 / 11,100 \%)$ was greater than that observed in age-matched controls $(11 / 33,33 \%)$ during exposure to hyperoxia at Denver atmospheric pressure (630 torr) for $10 \mathrm{~d}$ $(P=0.0009$; Fig. $1 A)$. Young male transgenic heterozygotes also had marginally significantly increased survival $(5 / 6,83 \%)$ when compared to age-matched controls $(3 / 8,38 \% ; P=0.054)$. In older ( $5.5 \mathrm{mo}$ age) female mice, survival of transgenic heterozygote mice decreased to $50 \%(8 / 16)$, whereas survival of controls was $27 \%(7 / 26$; Fig. $1 B$ ). At this age, there was no significant difference in survival distributions $(P=0.1102)$.

At sea level (760 torr) atmospheric pressure, no younger mice, transgenic heterozygote or control, male or female, survived for $>5 \mathrm{~d}$ in hyperoxia. Nonetheless, median survival was greater in transgenic heterozygote (female: $103 \pm 4 \mathrm{~h}$ [ $n=12$ ]; male: $106 \pm 4 \mathrm{~h}[n=14]$ ) than control mice (female: $90 \pm 3 \mathrm{~h}[n$ $=11]$; male: $88 \pm 4 \mathrm{~h}$ [ $n=10]$; data not shown in figures). The difference in survival distributions was marginally significant in females $(P=0.068)$ and significant in males $(P=0.013)$.

Histopathology. After oxygen exposure (630 torr) for $168 \mathrm{~h}$, pulmonary edema formation ( $56 \%$ of controls vs. $13 \%$ of transgenics, $P=0.013$, Pearson chi-square analysis) and hyaline membranes $(50 \%$ of controls vs. $13 \%$ of transgenics, $P=0.029$, Pearson chi-square analysis) were greater in control than transgenic mice. The lungs of the majority $(9 / 16)$ of these young female control mice had histopathologic evidence of severe confluent pulmonary edema and diffuse hyaline membrane formation as well as marked septal thickening, vascular conges- 


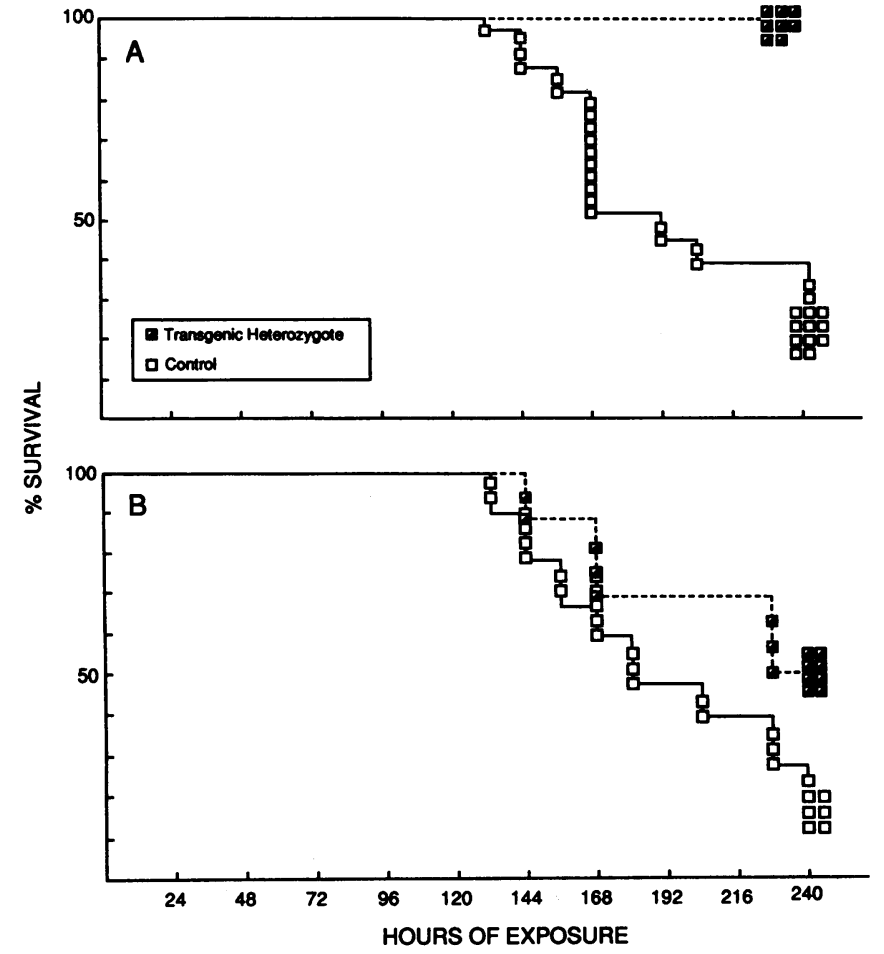

Figure 1. Effect of expression of elevated SOD levels on survival in hyperoxia. (A) Survival of young ( $2.5 \mathrm{mo}$ old $)$ transgenic heterozygote (TgHS-51) mice with constitutive expression of elevated SOD levels compared with control (CBYB6xB6D2) mice of the same genetic lineage during $10 \mathrm{~d}$ of exposure to hyperoxia $\left(>99 \% \mathrm{O}_{2}, 630\right.$ torr). (B) Survival of older (5.5 mo old) transgenic heterozygote (TgHS-51) mice with constitutive expression of elevated SOD levels compared with controls (CBYB6xB6D2) of the same genetic lineage during 10 $\mathrm{d}$ of exposure to hyperoxia (>99\% $\mathrm{O}_{2}, 630$ torr).

tion, and diffuse inflammation (Fig. $2 \mathrm{~A}$ ). Eight of these nine animals died within $<168 \mathrm{~h}$. The lungs of the remaining animals $(7 / 16)$ showed less severe pulmonary inflammation and vascular congestion. A minority (2/15) of young heterozygous transgenic mice had severe pulmonary edema and hyaline membrane formation comparable with that seen in the majority of controls. Only one of these two animals died during the 168-h exposure period. The lungs of the remainder (13/15) of the transgenic mice had less severe inflammation and vascular congestion comparable with that seen in the minority of controls (Fig. 2 B).

In older control female mice exposed to hyperoxia for 156 $h$, marked pulmonary edema and/or hyaline membrane formation occurred in the lungs of 2/7 animals, whereas it was present in none $(0 / 7)$ of the transgenic heterozygotes. There were no other histopathologic differences which could be distinguished between the two groups at this time, and no deaths had occurred in either group. Nonetheless, the numbers of neutrophils present in lungs of older transgenic heterozygote $(17 \pm 4 / 5$ high-power fields, $n=7$ ) mice were fewer than those counted in lungs of control $(90 \pm 29 / 5$ high-power fields, $n=7 ; P<0.05)$ mice. A similar trend occurred in the lungs of young transgenic (41 $\pm 5 / 5$ high-power fields) compared with control $(79 \pm 26 / 5$ high-power fields, $n=7 ; P=0.07$ ) mice after their exposure to hyperoxia for $168 \mathrm{~h}$. However, these analyses excluded all lungs from mice with gross pulmonary edema and hyaline membrane formation because substantial volume loss had occurred in those lungs.

Enzymatic differences in normoxia. Red cell SOD activity was increased in heterozygote transgenic mice compared with control mice from the same parent strain (SOD activity, $45,402 \pm 2,077 \mathrm{U} / \mathrm{g}$ hemoglobin, $n=9$, for heterozygotes; vs. $13,996 \pm 341 \mathrm{U} / \mathrm{g}$ hemoglobin, $n=15$, for controls; $P$ $<0.0001$ ). Although the differences in red blood cell SOD activity were great enough that transgenic heterozygote mice readily could be distinguished from control mice on the basis of these results, we confirmed the accuracy of this means of identification using electrophoretic identification of mouse and human CuZnSOD activity bands $(16,17)$ in samples of red blood cells and homogenates of lungs, kidneys, and other tissues from these mice.

Likewise, the total activity of SOD in lung tissue from young ( $2.5 \mathrm{mo}$ old $)$ transgenic heterozygous animals was found to be $310 \pm 25 \mathrm{U} / \mathrm{mg}$ DNA $(n=14)$ compared to $146 \pm 8 \mathrm{U} / \mathrm{mg}$ DNA $(n=20 ; P<0.0001)$ in controls using the ferricytochrome $c$ assay system. Using the more sensitive nitroblue tetrazolium assay system, CuZnSOD activity was increased similarly in lungs from young transgenic heterozygous animals $(1,330 \pm 117 \mathrm{U} / \mathrm{mg}$ DNA; $n=6)$ compared with controls (527 $\pm 37 \mathrm{U} / \mathrm{mg}$ DNA, $n=7 ; P<0.0001)$. However, absolute MnSOD activity was not different in lungs from these transgenic heterozygous mice ( $38 \pm 9 \mathrm{U} / \mathrm{mg}$ DNA, $n=6$ ) relative to controls $(44 \pm 8 \mathrm{U} / \mathrm{mg}$ DNA, $n=7 ; P=0.60)$. The increase in $\mathrm{CuZnSOD}$ activities in the lungs from transgenic compared with control mice also was apparent in the SOD activity gels upon which $\mathrm{CuZnSOD}$ and MnSOD migrate differently. Older transgenic heterozygote mice had similar, if not greater, absolute and relative increases in lung total SOD activity relative to controls as compared with their younger counterparts (Fig. 3, $A$; time 0 h columns).

In addition, lung glucose-6-phosphate dehydrogenase (G6PD; $0.240 \pm 0.014 \mathrm{U} / \mathrm{mg}$ DNA, $n=29$; vs. $0.156 \pm 0.011$ $\mathrm{U} / \mathrm{mg}$ DNA, $n=33$, for controls; $P<0.001$ ) and glutathione peroxidase (GPX; $1.67 \pm 0.09, n=29$; vs. $1.26 \pm 0.04, n=33$, for controls; $P<0.001)$ activities were greater in young $(2.5 \mathrm{mo}$ old) transgenic heterozygote compared with control mice during exposure to normoxia. Lung glutathione reductase, but not catalase, activities also tended to be higher in transgenic than control mice, but these differences were not significant. Constitutive overexpression of G6PD and GPX did not occur in older (5.5 mo old) transgenic mice relative to controls (Fig. 3, $B-E$; time $0 \mathrm{~h}$ columns).

Enzymatic differences in hyperoxia. Among transgenic heterozygote and control mice successfully adapting to hyperoxia, lung G6PD and GPX activities increased two- to threefold relative to baseline (normoxia) in young mice of both groups after $10 \mathrm{~d}$ (Fig. 3, $B$ and $C$, time $240 \mathrm{~h}$ columns). At that time, lung glutathione reductase activity also increased by $\sim 50 \%$ in both young transgenic and surviving control mice during oxygen adaptation (Fig. $3 \mathrm{D}$, time $240 \mathrm{~h}$ ). The rates of increase in lung activities of G6PD, GPX, and GR were not greater in young transgenic mice than controls (Fig. $3, B-D$, time $120 \mathrm{~h}$ columns). Smaller increases in lung catalase activity occurred also in control and transgenic mice after adaptation (Fig. $3, E$, time $240 \mathrm{~h}$ columns). However, total lung SOD activity did not increase in spontaneously adapting controls, and it tended to decline somewhat in the transgenic mice during adaptation. However, these decreases were not statistically significant 

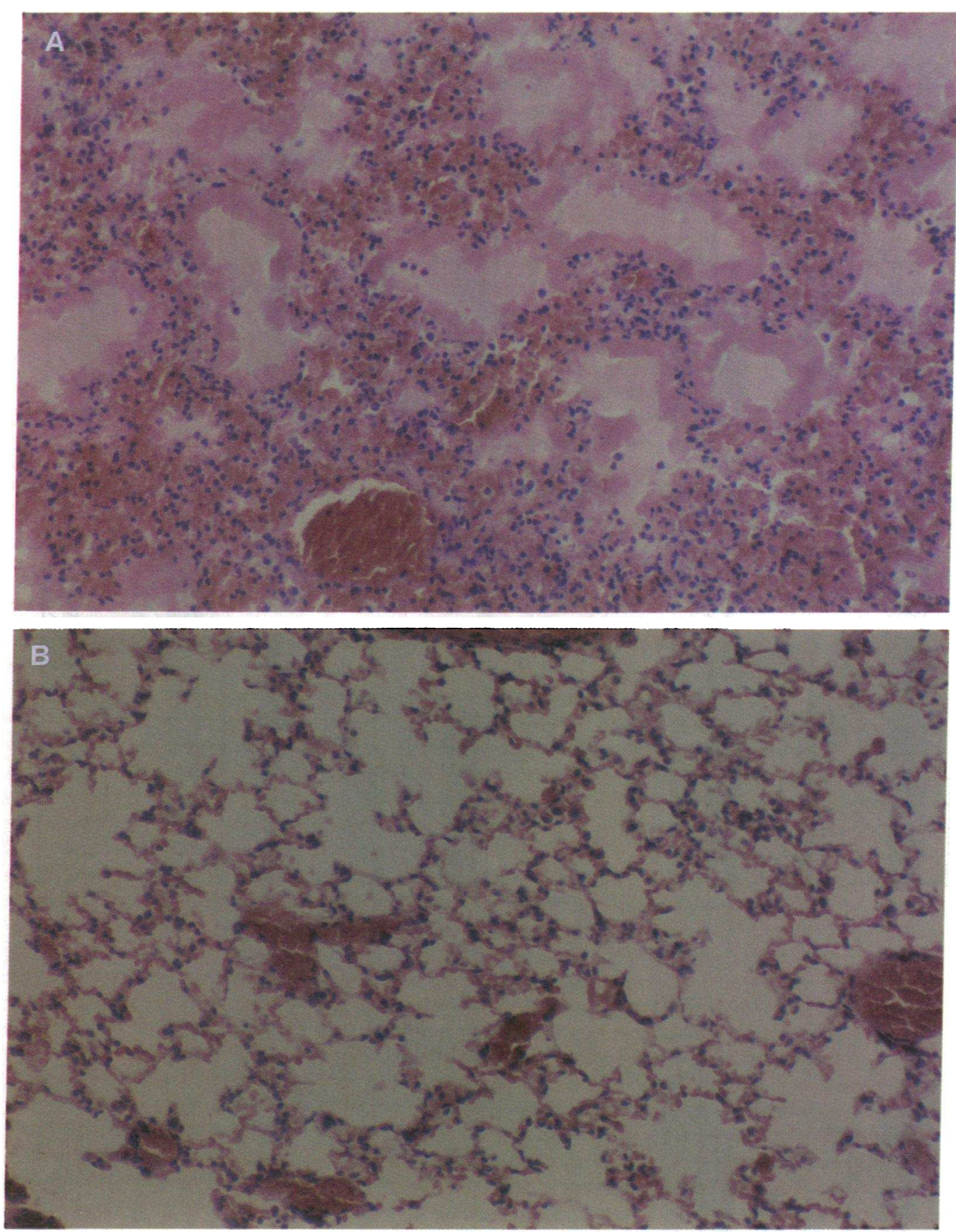

Figure 2. Effect of expression of elevated SOD levels on lung histopathology in hyperoxia. $(A)$ Photomicrograph of lung of young (2.5 mo old) control mouse exposed continuously to hyperoxia for $168 \mathrm{~h}$ and showing edema and hyaline membrane formation which occurred in $9 / 16$ oxygen-exposed controls ( $\times 50)$. (B) Photomicrograph of lung of young (2.5 mo old) heterozygous transgenic mouse after equal simultaneous hyperoxic exposure showing lesser inflammation, vascular congestion, minimal lung edema and absence of hemorrhage or hyaline membrane formation. Comparable changes were present in $13 / 15$ oxygenexposed heterozygotes. (Both are hematoxylin-eosin stained; magnification, 50 ; both lungs inflated at $15 \mathrm{~cm}$ water pressure).
(Fig. 3, A). Lung G6PD, GPX, and GR activities increased significantly $(P<0.05)$ in older transgenic, but not control, mice after $240 \mathrm{~h}$ of $\mathrm{O}_{2}$ exposure. Changes in lung SOD and catalase activities occurring in older mice of either group during oxygen exposure were not significant (Fig. 3, $A-E$ ).

\section{Discussion}

Expression of elevated levels of transgenic human CuZnSOD in mouse lung markedly prolonged survival of young mice in continuous normobaric hyperoxia at Denver $\left(>99 \% \mathrm{O}_{2}, 630\right.$ torr), but much less significantly at sea level atmospheric pressures ( $>99 \% \mathrm{O}_{2}, 760$ torr). Enhancement of survival was signif- icant in young ( $2.5 \mathrm{mo}$ old), but not older ( $5.5 \mathrm{mo}$ old), mice. Associated decreases in histopathologic evidence of acute lung injury were present in transgenic compared with control mice. These findings indicate that expression of elevated levels of CuZnSOD has a measurable, although limited, capacity to decrease mammalian pulmonary oxygen toxicity.

Further investigation of the lung enzymatic response of young mice to hyperoxic injury showed that adaptation of transgenic heterozygote mice to hyperoxia is associated with increases in lung glucose-6-phosphate dehydrogenase, glutathione reductase, and peroxidase activities. Similar increases in lung activities of G6PD, GR, and GPX also occurred in the small percentage $(33 \%)$ of spontaneously adapting control 
Ninit indli

ind In

inllil 
mice. Considerably smaller increases in lung catalase activity occurred during adaptation of young control and transgenic mice. Interestingly, total lung SOD activity did not increase in the spontaneously adapting control mice, and it tended to decline somewhat in the transgenics during adaptation. Thus, it appears that an endogenous, age-related adaptive process not involving lung SOD, but possibly involving the glutathione redox system, is superimposed on the oxygen tolerance in mice conferred by increased lung SOD activity. In addition to this effect in young mice, the constitutive overexpression of G6PD and GPX may contribute to the improved survival of young compared with older transgenic mice. It is unclear why constitutively increased levels of GPX and G6PD occur in normoxia only in the younger transgenic mice. However, constitutive overexpression of glutathione peroxidase has been observed recently in fibroblasts with increased expression of $\mathrm{CuZnSOD}$ (27). In our studies, increases in the glutathione redox cycle enzymes during exposure to hyperoxia were associated with the adaptation process. However, at the latest time point before which deaths began to occur in the control group (120 h), we did not find these increases to be occurring more rapidly or to a greater extent in transgenic compared with control mice. Because of attrition, it is not possible to know if severe lung injury in control mice of both ages or of older transgenic mice was associated with failure to induce glutathione redox cycle enzymes. This effect had not yet begun to occur by $120 \mathrm{~h}$ of exposure. After this time, mortality began to occur in each of these groups. Therefore, additional factors may be involved in the different levels of protection observed in the 2.5- and 5.5mo-old transgenic mice. Young mice and animals from multiple other species are much more likely than older animals to develop tolerance to lethal hyperoxic lung injury (9). Our findings strongly suggest that factors other than increased lung SOD activity alone may be required to explain these differences. Nonetheless, the combination of $(a)$ constitutively increased lung SOD activity, $(b)$ constitutively increased activities of lung glutathione redox cycle enzymes (G6PD and GPX), and $(c)$ additional increases in activities of lung glutathione redox cycle enzymes in response to hyperoxia (G6PD, GPX, and GR) occurred only in young transgenic mice, and only they showed prolonged tolerance to hyperoxia. Protection afforded by the first two factors, then, may have allowed the third effect to be manifested more completely in the young transgenic mice. However, we speculate that the age-dependent findings demonstrated here also could be a reflection of more rapid and efficient healing and repair mechanisms in the younger animals.

The evidence provided by these studies is more direct than many preceding mammalian studies in that SOD expression is the primary variable being manipulated. Additional sublethal stresses such as preexposure to hyperoxia, hypoxia, or endotoxin are not imposed, and alterations in membrane lipids or phagocyte functions, as may occur in liposome-bound enzyme augmentation, do not occur.
The mechanisms whereby protection against pulmonary oxygen toxicity by expression of elevated levels of transgenic superoxide dismutase occurs are not entirely clear. Certainly, abundant experimental data demonstrate that excessive quantities of toxic oxygen metabolites, including superoxide and hydrogen peroxide, are formed at multiple cellular sites during exposure of lungs or other organs to hyperoxic environments (28). Increased levels of CuZnSOD could decrease toxicity by decreasing superoxide available for damaging direct or indirect reactions with cellular constituents. In addition, it is possible that increased levels of SOD acted to decrease harmful secondary reactions of superoxide such as the formation of proinflammatory chemotaxins (29). Indeed, neutrophil chemotaxins and related inflammation may contribute to hyperoxia-related lung damage and death in mice exposed to oxygen for the relatively prolonged durations and under the same pressures as those used in this study (30). Nonetheless, the finding of smaller numbers of neutrophils in lungs from protected transgenic relative to control mice does not indicate if indeed these decreases occurred due to decreased concentrations of superoxide-dependent neutrophil chemotaxins or simply on the basis of decreased lung injury in the former.

Because production of toxic $\mathrm{O}_{2}$ products increases with oxygen tension (28), SOD and the glutathione redox system, even at increased levels of expression, probably were less capable of metabolizing these at the increased levels produced at the higher $\mathrm{O}_{2}$ tension studied ( 760 torr, sea level atmospheric pressure). This probably explains the poorer survival of animals exposed at 760 torr. Even at these higher pressures, there is no evidence from our studies that this level of increased lung CuZnSOD activity causes any enhanced toxicity or tissue injury in a hyperoxic environment.

Previously, we have evaluated three different in vivo models for tolerance to hyperoxic lung damage induced environmentally or pharmacologically in rats (preexposure to hypoxia, the cytokines IL-1 plus tumor necrosis factor, or to polyethylene glycol (PEG)-attached antioxidant enzymes [12, 13, 31, 32]). Protection, evidenced by decreased lung damage and mortality, was accompanied in each model by exogenously or endogenously increased superoxide dismutase. In tolerance induced by exogenously administered PEG-attached SOD and catalase, in which circulating, but not lung tissue, superoxide dismutase activity was increased appreciably by this treatment, protection was less impressive than in tolerance induced by hypoxia or cytokines, in which endogenous lung SOD activity did increase. Because lung-associated SOD activity was increased with the current intervention, this may explain the successful production of lung $\mathrm{O}_{2}$ tolerance in a species in which this does not normally occur outside the neonatal period (9).

In each model in which we evaluated lung antioxidant enzyme activities in oxygen-adapted animals, we found also that increases in activities of enzymes of the hexose monophosphate shunt and glutathione redox cycle occurred concomitantly with adaptive increases in superoxide dismutase activity.

enzyme (G6PD, GPX, and GR) activities occurred in young and older transgenic mice, and in the surviving $33 \%$ of young ( 2.5 mo old) control mice. However, these increases occurred only after $240 \mathrm{~h}$. Although significant during both intervals in young controls, the additional increase in GPX activity in young transgenic mice between times 0 and $240 \mathrm{~h}$ was not significant, whereas it was marginally significant $(P=0.06)$ between 120 and $240 \mathrm{~h}$. These enzymes did not increase in older control mice, except in the case of G6PD where a marginally significant $(P=0.06)$ activity increase occurred after $240 \mathrm{~h}$. Lung CAT activity increased significantly $(P<0.05)$ in young control and transgenic mice after $240 \mathrm{~h}$ compared with time 0 or $120 \mathrm{~h}$. Lung CAT did not change significantly in older mice. 
Thus, multiple systems, including the one described here, point to a strong interdependence between glutathione-dependent systems and superoxide dismutase in the evolution of endogenous tolerance to hyperoxic pulmonary injury.

Our results show a successful adaptation to hyperoxia in transgenic mice with constitutive expression of elevated levels of CuZnSOD. Therefore, therapeutic strategies involving induction of the host's own intracellular SOD(s) could be useful in preventing potential ill effects of treatment for the respiratory distress syndromes of both infants and adults. Furthermore, our findings with the CuZnSOD-transgenic mice suggest that, indeed, excessive superoxide, or one of its toxic products such as $\mathrm{HO}_{2}$. or $\mathrm{HO} \cdot$, causes or contributes to pulmonary oxygen toxicity.

\section{Acknowledgments}

The authors acknowledge the excellent technical assistance of Susan M. McMahon and Yvette Lewis-Molock who helped complete this work. The authors are grateful to Dr. Charles J. Epstein for helpful suggestions, to Dr. Connie Beehler for assistance with animal care issues, to Dr. Lynn Ackerson for the statistical analyses of survival data, to Dr. David Ikle' for statistical consultation, and to Larry Travis, Joni Canterbury, and Dr. Donald Maul for overseeing animal care in the barrier facility at Colorado State University.

This work was done during the tenure of an Established Investigatorship from the American Heart Association and was also supported by a Grant-in-Aid from the American Heart Association (C. W. White). Initial parts of this work were accomplished at the Webb-Waring Lung Institute with the help of a generous grant from the Ronald MacDonald Children's Charities to that institution. Additional research support was provided by the C. Henry Kempe Research Center of The Children's Hospital of Denver and by grants from the National Institutes of Health HD21229 (USA), the Minerva Foundation (Munich, FRG), and the Weizmann Institute's Leo and Julia Forcheimer Center of Molecular Genetics.

\section{References}

1. Rosenfeld, W., H. Evans, L. Concepcion, R. Jhaveri, H. Schaeffer, and A Friedman. 1984. Prevention of bronchopulmonary dysplasia by administration of bovine superoxide dismutase in preterm infants with respiratory distress syndrome. J. Pediatr. 105:781-785.

2. Shaffer, S. G., D. H. O'Neill, and D. W. Thibeault. 1987. Administration of bovine superoxide dismutase fails to prevent chronic pulmonary sequelae of neonatal oxygen exposure in the rat. J. Pediatr. 110:942-946.

3. Tanswell, A. K., D. M. Olson, and B. A. Freeman. 1990. Liposome-mediated augmentation of antioxidant defenses in fetal rat pneumocytes. Am. J. Physiol. 258:L165-L172.

4. Freeman, B. A., S. L. Young, and J. D. Crapo. 1983. Liposome-mediated augmentation of superoxide dismutase in endothelial cells prevents oxygen injury. J. Biol. Chem. 258:12534-12542.

5. Turrens, J. F., J. D. Crapo, and B. A. Freeman. 1984. Protection against oxygen toxicity by intravenous injection of liposome entrapped catalase and superoxide dismutase. J. Clin. Invest. 73:879-885.

6. Padmanabhan, R. V., R. Gudapaty, I. E. Liener, B. A. Schwartz, and J. R. Hoidal. 1985. Protection against pulmonary oxygen toxicity in rats by the intratracheal administration of liposome-encapsulated superoxide dismutase or catalase. Am. Rev. Respir. Dis. 132:164-167.

7. Tanswell, A. K., and B. A. Freeman. 1987. Liposome-entrapped antioxidant enzymes prevent lethal $\mathrm{O}_{2}$ toxicity in the newborn rat. J. Appl. Physiol. 63:347-352.
8. Crapo, J. D., and D. F. Tierney. 1974. Superoxide dismutase and pulmonary oxygen toxicity. Am. J. Physiol. 226:1401-1407.

9. Frank, L., J. R. Bucher, and R. J. Roberts. 1978. Oxygen toxicity in neonatal and adult animals of various species. J. Appl. Physiol. 45:699-704.

10. Frank, L., J. Summerville, and D. Massaro. 1980. Protection from oxygen toxicity with endotoxin: role of the endogenous antioxidant enzymes of the lung. J. Clin. Invest. 65:1104-1110.

11. Sjostrom, K., and J. D. Crapo. 1983. Structural and biochemical adaptive changes in rat lungs after exposure to hypoxia. Lab. Invest. 48:68-79.

12. White, C. W., J. H. Jackson, I. F. McMurtry, and J. E. Repine. 1988. Hypoxia increases glutathione redox cycle and protects rat lungs against oxidants. J. Appl. Physiol. 65:2605-2616.

13. White, C. W., P. Ghezzi, S. M. McMahon, C. A. Dinarello, and J. E. Repine. 1989. Cytokines increase rat lung antioxidant enzymes during exposure to hyperoxia. J. Appl. Physiol. 66:1003-1007.

14. Hass, M. A., J. Iqbal, L. B. Clerch, L. Frank, and D. Massaro. 1989. Rat lung $\mathrm{Cu}, \mathrm{Zn}$ superoxide dismutase. Isolation and sequence of a full-length $\mathrm{CDNA}$ and studies of enzyme induction. J. Clin. Invest. 83:1241-1246.

15. Epstein, C. J., K. B. Avraham, M. Lovett, S. Smith, O. Elroy-Stein, G. Rotman, C. Bry, and Y. Groner. 1987. Transgenic mice with increased Cu/Znsuperoxide dismutase activity: animal model of dosage effects in Down syndrome. Proc. Natl. Acad. Sci. USA. 84:8044-8048.

16. Avraham, K. B., M. Schickler, D. Sapoznikov, R. Yarom, and Y. Groner. 1988. Down's syndrome: abnormal neuromuscular junction in tongue of transgenic mice with elevated levels of human $\mathrm{Cu} / \mathrm{Zn}$-superoxide dismutase. Cell. 54:823-829.

17. Beauchamp, C., and I. Fridovich. 1971. Superoxide dismutase: improved assays and an assay applicable to acrylamide gels. Anal. Biochem. 44:276-287.

18. Crapo, J. D., J. M. McCord, and I. Fridovich. 1978. Preparation and assay of superoxide dismutases. Methods Enzymol. 53:382-393.

19. Lowry, O. H., N. J. Rosebrough, A. L. Farr, and R. J. Randall. 1951. Protein measurement with the Folin phenol reagent. J. Biol. Chem. 193:265-275. 20. Bergmeyer, H. U. 1955. Zur messung von katalase-aktivataten. Biochem. Z. 327:255-258.

21. Beutler, E. 1975. Red Cell Metabolism. A Manual of Biochemical Methods. Grune \& Stratton, New York. 160 pp.

22. Cross, C. E., T. T. Watanabe, G. K. Hasegawa, G. N. Goralnik, K. E. Roertgen, T. Kaizu, K. M. Reiser, A. B. Gorin, and J. A. Last. 1979. Biochemical assays in lung homogenates: artifacts caused by trapped blood after perfusion. Toxicol. Appl. Pharmacol. 48:99-109.

23. Oberley, L. W. 1988. Nitroblue tetrazolium. In CRC Handbook of Methods for Oxygen Radical Research. R. A. Greenwald, editor. CRC Press, Boca Raton, FL. 217-225.

24. Richard G. M. 1974. Modifications of the diphenylamine reaction giving increased sensitivity and simplicity in the estimation of DNA. Anal. Biochem. $57: 369-376$

25. Gross, A. J., and V. A. Clark. 1975. Survival distributions: reliability applications in the biomedical sciences. John Wiley \& Sons, Inc., New York. 331 pp.

26. Steel, R. G. D., and J. H. Torrie. 1960. Principles and Procedures of Statistics. McGraw-Hill Book Co. Inc., New York. 481 pp.

27. Kelner, M. J., and R. Bagnell. 1990. Alteration of endogenous glutathione peroxidase, manganese superoxide dismutase, and glutathione transferase activity in cells transfected with a copper-zinc superoxide dismutase expression vector. J. Biol. Chem. 265:10872-10875.

28. Freeman, B. A., and J. D. Crapo. 1981. Hyperoxia increases oxygen radical production in rat lungs and lung mitochondria. J. Biol. Chem. 256:1098610992.

29. Petrone, W. F., D. K. English, K. Wong, and J. M. McCord. 1980. Free radicals and inflammation: superoxide-dependent activation of a neutrophil chemotactic factor in plasma. Proc. Natl. Acad. Sci. USA. 77:1159-1163.

30. Parrish, D. A., B. C. Mitchell, P. M. Henson, and G. L. Larsen. 1984 Pulmonary responses of fifth component of complement-sufficient and-deficient mice to hyperoxia. J. Clin. Invest. 74:956-965.

31. White, C. W., P. Ghezzi, C. A. Dinarello, S. A. Caldwell, I. F. McMurtry, and J. E. Repine. 1987. Recombinant tumor necrosis factor/cachectin and interleukin 1 pretreatment decreases lung oxidized glutathione accumulation, lung injury, and mortality in rats exposed to hyperoxia. J. Clin. Invest. 79:1868-1873.

32. White, C. W., J. H. Jackson, A. Abuchowski, G. M. Kazo, R. F. Mimmack, B. A. Freeman, J. M. McCord, and J. E. Repine. 1989. Polyethylene glycol-attached antioxidant enzymes decrease pulmonary oxygen toxicity in rats. J. Appl. Physiol. 66:584-590. 